\title{
Resenha do livro "OECD-FAO Agricultural Outlook 2012-2021"
}

(D) livro "OECD-FAO

Agricultural Outlook 20122021" foi produzido pela secretaria geral da Organização das Nações Unidas para Alimentação e Agricultura (FAO). Ele reúne informações relacionadas com a produção e consumo de alimentos, assim como combustíveis obtidos de fontes renováveis em todo o mundo. A FAO é um importante órgão da ONU que busca obter melhorias nas zonas rurais, traçando objetivos de longo prazo para o aumento da produção de matérias-primas de fontes renováveis, assim como a preservação dos recursos naturais. Seu quadro técnico é formado por engenheiros florestais, agrônomos, químicos, e outros profissionais, que são responsáveis pela coleta, análise e disseminação de informações através de newsletters, revistas e livros.

O livro possui em seus nove capítulos uma visão da produção global de oleaginosas, biodiesel, açúcar, proteínas e cereais. Nos primeiros capítulos é possível obter dados relacionados com a área plantada em todo mundo e o aumento de produtividade de cada país por um período de mais de 50 anos. Os setores de biodiesel e produção de oleaginosas estão nos capítulos 3 e 5, respectivamente, com informações atualizadas do mercado mundial, tendências, possíveis riscos na produção, além de perspectivas para os próximos dez anos.

É importante destacar que o Brasil ocupa uma posição de destaque no livro devido à sua importante contribuição para a geração de alimentos a baixos custos, alinhando alta tecnologia e alta produtividade. Para os investidores, o livro torna-se uma importante fonte de informações na hora de investir em produtos a base de fontes renováveis, e para os que estão no mercado, o livro traz informações atualizadas que podem auxiliar no processo de globalização de seus produtos. Para os pesquisadores, são fornecidas informações importantes de mercado, para que eles alinhem suas pesquisas às novas tendências para os próximos dez anos das matériasprimas, principalmente aquelas dos setores voltados para oleaginosas e seus derivados.

Com esse livro a FAO realizou um excelente trabalho disponibilizando dados relacionados com a agricultura e alimentação, podendo servir como base para o fomento de políticas de longo prazo, além de favorecer setores industriais, científicos e tecnológicos, na busca de se obter novos produtos utilizando matérias primas de fontes renováveis.

\footnotetext{
Universidade de Brasília, Instituto de Química, Brasília-DF, Brasil.

Mviniciusmmello@gmail.com

DOI: $\underline{10.5935 / 1984-6835.20130014}$
} 